\title{
OS OUTROS: O MELHOR DE MIM SOU ELES (ENCONTROS, ACASOS E SILÊNCIOS NA ESCRITURA DE MANOEL DE BARROS) $)^{1}$
}

\author{
OTHERS: THE BEST OF ME IS THEM \\ (ENCOUNTERS, CHANCE, AND SILENCES IN \\ MANOEL DE BARROS' WRITING)
}

\begin{abstract}
Valdegilson da Silva Costa
Pontifícia Universidade Católica de São Paulo, São Paulo, São Paulo, Brasil

gilsonvcosta@gmail.com

Vera Lúcia Bastazin

Pontifícia Universidade Católica de São Paulo, São Paulo, São Paulo, Brasil

vbastazin2@gmail.com
\end{abstract}

Resumo: Este trabalho analisa a maneira como a alteridade se inscreve na obra de Manoel de Barros, especificamente, no poema "Lições de R.Q", integrante da seção "Os Outros - o melhor de mim sou Eles". Tomando-se por base procedimentos artísticos de Rômulo Quiroga nas artes plásticas e a poesia de Manoel de Barros, o estudo enfoca o encontro destas duas identidades: a do eu-lírico e a do artista plástico. Pode-se afirmar que este encontro resulta na evocação de tempos e espaços recônditos e, simultaneamente, latentes diante das feições por meio das quais ambos se edificam como alteridades inatingíveis e indizíveis, conforme conceituam Emmanuel Lévinas e Maurice Blanchot.

Palavras-chave: Literatura e Alteridade; Literatura e o Indizível; Literatura e Silêncio; Escritura

Abstract: This paper analyzes the way through which otherness encompasses Manoel de Barros' work, specifically, in the poem "Lições de R.Q", a component of the section "Os Outros - The best of me is They". Based on the artistic procedures of Rômulo Quiroga in the visual arts and the poetry of Manoel de Barros, this study focuses on the confluence of identities (that of the lyrical self and that of the visual artist) which results in the evocation of hidden times and spaces and, simultaneously, remains latent before the features through which both are built as unattainable and unspeakable otherness, as conceptualized by Emmanuel Lévinas and Maurice Blanchot.

Keywords: Literature and Othernes; Literature and the Unspeakable; Literature and Silence; Scripture

\footnotetext{
${ }^{1} \mathrm{O}$ título deste artigo retoma diretamente nosso objeto de investigação, qual seja, a obra de Manoel de Barros, Livro sobre nada que, em sua quarta parte, se intitula "Os outros: o melhor de mim sou eles".
} 


\section{Alteridades: prolongamentos vazios}

Manoel de Barros é considerado poeta de primeira grandeza, na literatura brasileira, não apenas por inscrever as cores e os valores da sua terra como pedras preciosas que ofuscam na pequenez de suas descobertas, mas sobretudo, por atingir em sua poeticidade a imagem do homem como um ser em permanente interação com o outro. Entendido como elemento pertencente a natureza bruta e como alguém próximo aos animais que o rodeiam, este homem é, também, inscrito na obra como um outro eu construtor cultural de um universo marcado pelo sensível que tudo carrega em sua varredura do universo cognoscível. O objeto poético selecionado como referência central para este artigo é o poema "As lições de R.Q", de Manoel de Barros e, as referências teóricas básicas, o conceito de alteridade, de Emanuel Lévinas e a ideia do inapreensível de Maurice Blanchot.

A relação entre o eu e o outro é uma questão que se impõe em praticamente toda a obra do poeta e, de forma bem peculiar, no subtítulo da quarta parte do Livro sobre nada (1996). Os estudos de ordem teórica aproximam o outro de uma espécie de abstração, de uma generalização, dele retirando quaisquer traços de realidade própria. Eles tendem, ainda, a realizar uma violação do outro, ao aprendê-lo em sua parcialidade, já que, ao invés de invocálo em presença, passam a nomeá-lo por meio de referências intrínsecas a quem o constrói, de tal modo que, sua imagem torna-se posse de quem o apreende, conforme propõe Lévinas (2004). Esta abstração do outro, anula-o como significação própria, abarcando-o numa horizontalidade que apenas o generaliza, ao invés de lhe dar feição, rosto, singularidade.

A escritura se "instala descobrindo sob as aparentes pessoas a potência de um impessoal, que de modo algum é uma generalidade, mas uma singularidade no mais alto grau [...]”, declara Deleuze (1997, p. 13). As palavras do filósofo francês apontam na escritura uma discernibilidade de sujeitos, os quais se encontram, de acordo com ele, na imprevisibilidade, numa espécie de vizinhança da qual brota, no sujeito lírico, uma terceira pessoa, resultante do contato consigo e com os eus que o circundam.

Considerando-se o subtítulo "Os Outros: o melhor de mim sou Eles", estamos diante de um ser que se instaura de modo despersonalizado (o autor) e que se reconstrói frente à escritura. Estamos mesmo em face a um deslocamento, uma despersonalização que degrada o ser, conduzindo-o à individualidade pelas vias da escritura, fenômeno examinado ao longo deste artigo que intenta lançar alguma reflexão acerca do poema "As lições de R. Q.” (2001, p. 75), texto integrante de Livro sobre nada (1996), de Manoel de Barros.

Sob pretexto de escrever um Livro sobre nada (1996), Manoel de Barros escava sulcos no interior da língua, criando choques nos modelos convencionais de percepção. A sintaxe conflitante gera efeitos de subordinações semânticas e frásicas inapreensíveis, das quais surgem associações das mais inesperadas, muitas vezes marcadas pela impossibilidade de discernimento do ponto de vista lógico. O leitor responde a essa quebra da lógica com o silêncio de quem fora atravessado pelo indizível, pelo fabuloso edificado sob a condição de reinvenção da língua como experiência.

Na parte introdutória à obra - denominada como "Pretexto" (2001) -, o poeta afirma "O que eu queria era fazer brinquedos com as palavras. Fazer coisas desúteis. O nada mesmo. Tudo que use o abandono por dentro e por fora" (p. 4). Nesse texto, é latente a ludicidade inerente à escritura. O homem lúdico, lembremos, é aquele a quem o jogo, extrapola a realidade social, configurando-a como forma de imaginação, trata-se de um sujeito que, para compreender a realidade, necessita abandoná-la e reconstruí-la paralelamente na e pela 
linguagem. "O nada mesmo", ao invés de acentuar qualquer insignificância, cria um espaço de prolongamento do vazio, no qual se projetam as essências invisíveis, estendendo-as a outros seres. Considerando-se que metáfora "é a transferência de significação por meio de elipses do elemento comparativo", conforme Carlos Ceia (E-dicionário de Termos Literários, 2010), a figura de linguagem é também deslocamento para fora de si. Graças ao procedimento metafórico, é possível vincular seres das mais diversas ordens e categorias. Diluem-se os contornos racionais, generalistas que demarcariam os seres. Anula-se uma realidade plenamente constituída pela repetição em nome de uma constituição outra dos fatos, da vida, das relações.

As palavras que compõem o "Pretexto" do Livro sobre nada (1996) também questionam o caráter utilitarista da linguagem. O desejo do poeta de "criar coisas desúteis" em sua escritura evidencia seu desgosto em relação às demarcações da linguagem. As "coisas desúteis" não são, necessariamente, inúteis. São, antes, aquelas cujo caráter ínfimo somente se constitui em razão da elevação da pequenez materializada na linguagem. Restos, mosquitos e patas de insetos constituem o imperceptível cotidianamente, mas sob o prisma da distância sob a égide de quem do real se distancia para nele adentrar - estabelecem uma deformação do princípio generalizante, assumindo-se a fragilidade da palavra cotidiana frente às múltiplas possibilidades do ser designado. Assim sendo, da escritura jorram instabilidades que transformam e transtornam o sujeito-lírico a ponto de ele se abster da linguagem referencial.

A quê abandono interno e externo estaria o poeta se referindo ao enunciar "Tudo que use abandono por dentro e por fora" $(2001$, p. 4)? A nosso ver, a referência manoelina se insere naquilo a que Blanchot (1987) intitularia ausência pura: abandonam-se as emoções (abandono interno); abandonam-se as vivências (abandono externo) para que se dilua constantemente a subjetividade e a escritura se situe em busca do que Agamben define como gesto: "aquilo que continua inexpresso em cada ato de expressão" (2007, p. 59).

\section{Da pintura primitiva de Quiroga à palavra iluminada de Barros}

Doravante, voltemos nossa atenção à nota introdutória ao poema "As lições de R. Q", texto inicial da quarta parte do Livro sobre nada (1996), intitulada, como já explicitamos, "Os outros: o melhor de mim sou Eles":

Nota: Um tempo antes de conhecer Picasso, eu tinha visto na aldeia boliviana de Chiquitos, perto de Corumbá, uma pintura meio primitiva de Rômulo Quiroga. Era um artista iluminado e um ser obscuro. Ele mesmo inventava as suas tintas. Trazia dos cerrados: seiva de casca de angico (era o seu vermelho); caldas de lagartas (era o seu verde); polpa de jatobá maduro (era o seu amarelo). Usava pocas de piranha derretidas para dar liga aos seus pigmentos. Pintava sobre sacos de aniagem. Mostroume um ancião de cara verde que havia pintado. Eu disse: mas verde não é a cor da esperança? Como pode estar em rosto de ancião? A minha cor é psíquica - ele disse. $\mathrm{E}$ as formas incorporantes. Lembrei que Picasso depois de ver as formas bisônticas na África, rompeu com as formas naturais, com os efeitos de luz natural, com os conceitos de espaço e de perspectiva, etc etc. E depois quebrou planos, ao lado de Braque, propôs a simultaneidade das visões, a cor psíquica e as formas incorporantes. Agora penso em Rômulo Quiroga. Ele foi apenas e só uma paz na terra. Mas eu vi latejar rudemente nos seus traços milagres de Klee. Salvo não seja. (BARROS, 2001, p. 74). 
O sujeito-lírico adentra o iluminado obscuro, conduzindo, na nota, aquilo que extrapola a expressão representada sob forma de um rosto ancião. A própria técnica, assim como os meio de produção, no entanto - que dizem muito sobre Quiroga -, são o conteúdo inexpresso porque dito no fazer das coisas, nas escolhas por ele feita. Conteúdo que fala por meio da forma e materiais pouco convencionais que compõem a obra que edificam o outro Quiroga, no caso. O claro rosto ancião diz algo sobre a relação vida (esperança) - morte (velhice), mas o inexpresso é o que acentua a alteridade do pintor. São as gosmas extraídas das lagartas, as cascas e os frutos maduros de onde se extraem as cores que fazem emergir no eulírico um mundo fora das perspectivas por ele adotada. Nesse sentido, é válido retomar o que Peter Pelbart estabelece sobre a neutralidade da relação do eu com o outro:

[...] Relação com o estranho, o estrangeiro, a alteridade, com aquilo que irremediavelmente estará fora, do meu espaço, do meu tempo, da minha consciência, do meu eu, da minha palavra, do meu controle. Estará fora do meu mundo, de forma desconhecida, impessoal, na mais próxima distância, na mais ausente das presenças, como aquilo que excede o meu pensar, convulsiona meu sentir, desarma meu agir (PELBART, 1989, p. 98).

A alteridade é compreendida, no excerto, "como aquilo que excede o meu pensar, convulsiona meu sentir, desarma meu agir". Parece-nos que o outro perturba a existência do eulírico porque desestabiliza o modo como este age em razão de um excesso de pensamento inatingível ao sujeito-poético. Excesso pelo qual ele perpassa como realidade incessantemente estranha, tomada como lição, como aprendizado de desaprender ensinada por Rômulo Quiroga, "[...] um artista iluminado e um ser obscuro." Quiroga existe como artista, como pintor de paredes, mas em termos pragmáticos é um ser que extrapola os próprios sentimentos e vivências manoelinas. Na nota, o artista da província de Chiquitos dá luz à obscuridade experienciada por Barros. É uma presença em ausência, a qual o autor situa entre dois outros grandes artistas: Pablo Picasso e Paul Klee, num jogo em que o efeito estético advém da interpenetração do universo ficcional naquilo que chamamos de mundo das artes plásticas.

Não é surpresa a ninguém o diálogo entre a arte primitiva e a intitulada arte moderna do início do século XX, especialmente no que se refere ao Cubismo, tendência encabeçada por Pablo Picasso (1881-1973) e Georges Braque (1882-1963), cuja ruptura de paradigma com a arte convencional é pautado na colagem, na utilização de materiais pouco convencionais que se encontravam à volta dos artistas. Esta atitude perante a arte propunha, graças à técnica da colagem, a sobreposição, a justaposição e a fragmentação de imagens. Rômulo Quiroga adotara semelhante prática. A poética de Manoel de Barros, a exemplo de seu artista ficcional sobrepõe tempos. Notemos, o anacronismo que o poeta comete ao afirmar que se lembrara de Picasso antes mesmo de o conhecer. Este procedimento, ao invés de sugerir qualquer incoerência ao texto introdutório, é a manifestação de uma paradoxal lembrança - aquela que ainda não se viveu. Corporificando-se, na escritura, a independência do autor em relação ao mundo das experiências revela neste caso, no próprio sujeito-lírico, certa propensão a sentir forte presença do que se ausenta nele, como se o presente fosse o pressentimento de uma profunda ausência.

O artista plástico suíço, Paul Klee (1879-1940), conquanto não possa ser classificado sob a perspectiva de nenhuma das vanguardas, possui estreito vínculo com várias delas, especialmente no tocante à ruptura com a tradição. Ao invocar Klee à nota, Manoel de Barros conclama um artista que se abstém do objeto que dele prescinde. $\mathrm{O}$ abstracionismo de Paul Klee captura o avesso do visível, suas formas expõem o mistério das coisas, ou mesmo a transitoriedade das coisas e das formas. Esta busca pelo avesso do visível, pela arte como ponto 
de passagem, coincide, a nosso ver, com aquilo que o poeta do Pantanal constrói em sua escritura. $\mathrm{O}$ inapreensível da realidade, de acordo com a nota, configura um milagre, uma espécie de experiência fora do comum, distante da lógica natural, assim como se impõe a escritura manoelina.

Nas palavras de Quiroga, a "cor é psíquica" e "as formas incorporantes", o que significa dizer que a cor e as formas não são apenas elementos presentes, mas elementos que re-presentam. A representação é um índice de intencionalidade que convoca elementos diversos à imagem, sem que haja entre eles um conjunto de contiguidades. Desta forma, verde não pertence ao eixo dos elementos que simbolizam a esperança, assim como vermelho, por exemplo, assumiria significações outras, que não as passionais. Essa aparente distorção nas relações contíguas causa estranheza ao sujeito-lírico que, ingenuamente, associa verde a esperança e indaga Quiroga quanto à aplicação de traços esverdeados ao rosto de um ancião.

Barros, em verdade, está nos mostrando o quanto a tarde não anuncia a noite, o quanto o início não anuncia o fim, já que "nosso campo perceptivo é feito de coisas e de vazios entre coisas" (PONTT, 2018, p. 38). Assim, é possível conhecer algo nunca visto; é possível enxergar as formas de um objeto incorporando outro, justamente como nas obras cubistas de Braque e de Picasso ou na inominável arte de Paul Klee. Vislumbramos aqui um ponto de tensão entre o visto e o visível. $\mathrm{O}$ visto recobre a percepção de um mesmo olhar depositado sobre o outro. $\mathrm{O}$ visível, por sua vez, é a abertura a que o outro se mostre neste campo vazio a ser ocupado com sua subjetividade. O próprio Barros discorre sobre o tema em entrevista à revista Caros Amigos (2008)

\begin{abstract}
Aprendi que o artista não vê apenas. Ele tem visões. A visão vem acompanhada de loucuras, de coisinhas à toa, de fantasias, de peraltagens. $\mathrm{Eu}$ vejo pouco. Uso mais ter visões. Nas visões vêm as imagens, todas as transfigurações. O poeta humaniza as coisas, o tempo, o vento. As coisas, como estão no mundo, de tanto vê-las nos dão tédio. Temos que arrumar novos comportamentos para as coisas. E a visão nos socorre desse mesmal. (BARROS, 2008, p. 23).
\end{abstract}

É importante notar como todos os invocados na narrativa/ nota assumem significados em razão daquilo que não são: Manoel de Barros despersonaliza-se; assume-se Quiroga. Quiroga remete às obras bisônticas que, por sua vez, remontam a Picasso e a Braque. Todos os seres caminham num movimento de reconhecimento do outro, graças a um enlace de aberturas a conciliações improváveis até que se misturem, silenciem, coloquem-se em suspensão para que brote a escritura - a imagem -, sem que dela conheçamos o início ou fim, conforme esclarece Blanchot:

Quando numa obra lhe admiramos o tom, sensíveis ao tom como ao que ela tem de mais autêntico, o que queremos designar por isso? Não o estilo, nem o interesse e a qualidade da linguagem mas, precisamente, esse silêncio, essa força viril pela qual aquele que escreve, tendo-se privado de si, tendo renunciado a si, possui nesse apagamento mantido, entretanto, a autoridade de um poder, a decisão de emudecer, para que nesse silêncio adquira forma, coerência e entendimento aquilo que fala sem começo nem fim (BLANCHOT, 1987, p. 18).

Estes movimentos do ser lírico, circundados por sua singularidade, conquanto assumam a exterioridade dão rosto à poética manoelina. Rosto audível, proveniente do contato 
direto do escritor com Quiroga, da participação daquele no mundo deste, ao que examinaremos, na sequência, adotando-se como referência o poema a seguir:

\author{
As lições de R. $Q$. \\ Aprendi com Rômulo Quiroga (um pintor boliviano): \\ A expressão reta não sonha. \\ Não use o traço acostumado. \\ A força de um artista vem das suas derrotas. \\ Só a alma atormentada pode trazer para a voz um \\ formato de pássaro. \\ Arte não tem pensa: \\ O olho vê, a lembrança revê, e a imaginação transvê. \\ É preciso transver o mundo. \\ Isto seja: \\ Deus deu a forma. Os artistas desformam. \\ É preciso desformar o mundo: \\ Tirar da natureza as naturalidades. \\ Fazer cavalo verde, por exemplo. \\ Fazer noiva camponesa voar - como em Chagall. \\ Agora é só puxar o alarme do silêncio que eu saio por \\ aí a desformar. \\ Até já inventei mulher de sete peitos para fazer vaginação \\ comigo.
}

(BARROS, 1996, p. 75)

Compreendido na esteira da metalinguagem, o poema pontua, nos versos "A expressão reta não sonha" e "Não use o traço acostumado", o que pode significar a absorção das experiências de Quiroga pelo eu-lírico. De início, chamam atenção os termos "reta" e "traço", possíveis referências ao uso de formas geométricas e à fragmentação Cubista, bem como a palavra "sonho", alusiva ao teor onírico do Surrealismo. Entendido à luz das propostas cubista e surrealista, o primeiro verso acentua o caráter fragmentado, descontínuo, caleidoscópico, ilógico da escritura, enfatizando a impossibilidade de representação direta inerente à linguagem artística. Impossibilidade essa resultante do postergamento próprio da linguagem, que recolhe em si apenas ausências sob forma de signos, de pactos linguísticos a partir dos quais a significação galga rumos, conforme preconiza Blanchot (2011, p. 331): "a palavra me dá o que ela significa, mas primeiro o suprime".

O segundo verso, em forma de aconselhamento, enfatiza, a necessidade de alheamento da irrupção em outro ser como procedimento poético; como se os hábitos do sujeito poético, diante da poesia, não pudessem coincidir com os do sujeito civil. Fragmentar-se e alhear-se são maneiras de não acolher o mesmo, de propor a arte literária como forma inconstante, errante, fora de costumes, com o intuito de lançar a linguagem para além do texto - seja para o escritor, seja para o leitor.

Os três versos que se seguem "[...] A força de um artista vem de suas derrotas/ Só a alma atormentada pode trazer para a voz um/ formato de pássaro/ [...]" reiteram o que já afirmamos sobre alheamento e fragmentação. O termo derrota significa, dentre outras coisas, aniquilação, ruína, fracasso. Paradoxalmente, é da ruína, dos interstícios do fracasso que surge a força e a literarierade do texto. Também é paradoxal a insensatez de acordo com a qual o sublime - o Belo da poiesis -, representado pelo que seria a voz em formato de pássaro, é 
proveniente da "alma atormentada", incorporando movimento à voz, numa composição de caráter sinestésico. Essa imagem poética é constituída por inferências e alusões que, vagamente, representam a dimensão acústica do canto das aves. A tormenta, a exemplo da derrota, é o avesso do que corriqueiramente expressa. Ambas assumem a instância da negação das convenções disfóricas com que frequentemente são abordadas, do que resulta um impacto no próprio código e de suas convenções. Pacto sustentado pelo ilogismo, afinal "Arte não tem pensa", que sugere uma dissociação entre o sensível e o cognoscível.

$\mathrm{O}$ verso seguinte "O olho vê, a lembrança revê, e a imaginação transvê" é emblemático. Gradativamente, o olhar se apura no verso. Inicialmente, a asserção "o olho vê", soa como algo de simples compreensão, não fosse a complexidade que a própria raiz etimológica do termo "olho" resguarda. Occulum (termo latino para designar "olho") possui o mesmo radical que o termo occultus (oculto). Haveria, então, no simples ato de olhar, um movimento que desvenda e outro que oculta. Mais uma vez, paradoxalmente, ver é "ao mesmo tempo sair de si e trazer o mundo para dentro de si”, conforme Chauí (1988, p. 33), no ensaio "Janela da alma, espelho do mundo".

Ver, portanto, não só se entrelaça à despersonalização do poeta, mas também à maneira como ele oculta o mundo dentro de si. No mesmo verso, a referência ao olhar se condensa em outra asserção: “[...] a lembrança revê [...]". O acréscimo do prefixo re indica recordação por intermédio da lembrança, mas não se pode deixar de levar em conta o fato de que rever também significa modificar, revisar, de tal modo que a lembrança, referência explícita ao passado, é revista no e pelo presente. O preterido, o que se deixou como resto é também parte do que o sujeito é. Trata-se de uma confluência de tempos que transvê e a transvisão é aqui compreendida como visão que se alarga para além do visível. A alusão ao que se vê surge da imaginação, do ato de criar imagem.

[...] a essência da imagem é estar toda para fora, sem intimidade, e no entanto mais inacessível e mais misteriosa do que o pensamento do foro interior; sem significação, mas chamando a profundidade de todo sentido possível; irrevelada e, no entanto, manifesta, como a presença-ausência que constitui o atrativo e o fascínio das Sereias. (BLANCHOT, 2005, p. 19).

A dubiedade - revelação/ocultação - orienta o sujeito-lírico à desformação, à desnaturalização do olhar. Guiado pela transvisão, o nítido se desfaz em imagens que correspondem a um outro mundo; a um tempo outro. As formas habituais de se relacionar com o mundo são esvaziadas de sentido; da natureza, são retiradas as naturalidades. Occullum e occultus imbricados na desconstrução dos paradigmas. Nos interstícios, nos restos, nos fragmentos resultantes da desformação está a chave para a compreensão do todo e do outro. Todo este que omite sua integridade, posto que se apresenta em partes, por meio de imagens que permitem acessar uma ordem existente sim, apesar de ausente no olhar marcado pela nitidez. O outro, por sua vez, se constrói quando o sujeito - lírico se desfaz, ou melhor, se esvazia a ponto de assumir que seu melhor não está em si, mas n'Eles (outros). Esvaziar-se para acessar outra ordem, em que predominam cavalos verdes; imagens oníricas como as de Chagall são a materialização da presença do outro, da exterioridade na interioridade manoelina.

Após a longa estrofe anterior, temos outra, composta por um único verso: "Agora é só puxar o alarme do silêncio que eu saio por aí a desformar." O alarmante do silêncio advém da força com que a experiência concreta com Rômulo Quiroga, ao menos em termos ficcionais, se espalha no interior do aprendiz (eu-lírico). São tantas as presenças a que esta relação invoca por meio de um simples diálogo, que seus resultados propulsionam a presença não de outro, mas 
de outros na já esvaziada subjetividade do aprendente. Esvaziada, a individualidade trai e retorna a si, conforme Lévinas (2004, p. 38). Esta separação de si e conciliação consigo manifesta-se no silêncio que toma conta do ser lírico. O silêncio é, então, a mistura de sensações que amplia o outro dentro do sujeito. É a pausa para o acolhimento. Acolhe-se o diferente, não limitado a um outro $\mathrm{eu}$, mas como o outro outro, aceito na individualidade dele, já que seu rosto não se instaura como reminiscência, mas como "conhecimento do novo" (LÉVINAS, 2004, p. 38). É no desencontro consigo que o ser lírico encontra e pratica a linguagem fôntica, reintegrase às formas bisônticas, ao primitivo, ao mito, por meio de um incessante retorno às matrizes, assegurando seu caráter inacabado, a exemplo do que afirma o pantaneiro no excerto abaixo:

Tenho em mim um sentimento de aldeia e dos primórdios. Eu não caminho para o fim, eu caminho para as origens. Não sei se isso é um gosto literário ou uma coisa genética. Procurei sempre chegar ao criançamento das palavras (BARROS, 2008, p. 8).

O retorno aos primórdios, acompanhado pelo "criançamento das palavras", assegura à escritura manuelina um processo de fabulação intrincada ao mito e à infância de que resulta a perspectiva de reconstrução do mundo graças à fabulação. $\mathrm{O} e u$ busca a infinitude. Para ele, as experiências vividas não se esgotam, antes, se atualizam no tempo. Não são o cognoscível, nem o reminiscente, mas o que lhe permite conhecer a totalidade, sem que para isso faça uso da razão, elemento, em essência, aprisionador. Adere à inocência da percepção infantil e à ritualística do retorno mítico para construir seu estar no mundo, sua ética.

O último verso do poema "Até já inventei mulher de 7 peitos para fazer vaginação comigo" é a manifesta aproximação entre poesia e erotismo. A linguagem poética é prenhe de significações. Sua sensualidade está em revelar a essência dos seres por intermédio de uma linguagem essencialmente misteriosa. Os seios são, em essência, a fonte que nutre a vida e uma das marcas de corporeidade feminina. O feminino é fonte de vida, no caso do poema, ainda que em forma nonsense (mulher de sete peitos) é de onde nascem as novas perspectivas poéticas do sujeito-lírico, o qual confirma dentro de si o eu que estava fora, ou seja, as lições de Quiroga reconstituídas metaforicamente, de modo a iniciar certo distanciamento, certa liberdade por parte do eu-lírico que sai "por aí a desformar", numa atitude que o emancipa das lições e o permite "existir existindo". Trata-se de um distanciamento que mantém presença disseminada, anacrônica à qual apenas um longo exercício de escavação promoveria acesso. "Fazer vaginação", isto é, gerar aberturas materializa o desejo de "Outro" no eu-lírico, o desprendimento com a imagem reflexa, mais que isso, o desejo incessante do imaginário e da invenção.

Diríamos que se trata de uma entranhada do outro, na linguagem e na percepção, infinitamente calcada na experiência de outrem - Quiroga. Não o conceito Quiroga, mas a conversa com ele, o fazer dele, distante de qualquer conceitualidade, de qualquer generalização; plena atitude de fecundidade em relação à linguagem e em relação ao pensamento do pintor, incessantemente incompreensível, inapreensível, já que é um ser pensante, inefável.

Nas sendas das lições, desaparecem Quiroga e o eu-lírico. O aprendizado inaudível, sem síntese, manifesto pelo teor de ruptura das imagens criadas por nosso apreciador/leitor/sujeito lírico desfaz as pontes que apreenderiam seu mestre, cuja lição é a invenção do impossível em infinitas perdas e fissuras que profanam o ser e a linguagem. 


\section{Referências}

AGAMBEN, G. O autor como gesto. In: AGAMBEN, G. Profanações. Tradução e apresentação de Selvino José Assmann. São Paulo: Boitempo, 2007.

BARROS, M. Livro sobre nada. Rio de Janeiro: Record, 2001.

BARROS, M. 2008. Entrevistas concedidas a Martins Bastos; Douglas Diegues e Cláudia Trimarco, nov. Disponível em: www.elfikurten.com.br. Acesso em 03 dez. 2018.

BLANCHOT, M. O espaço literário. Tradução de Álvaro Cabral. Rio de Janeiro: Rocco, 2011.

BLANCHOT, M. A parte do fogo. Tradução de Ana Maria Scherer. Rio de Janeiro: Rocco, 1987.

BLANCHOT, Maurice. O livro por vir. Tradução de Leyla Perrone-Moisés. São Paulo: Martins Fontes, 2005.

CEIA, C. 2010. E-dicionário de termos literários. Disponível em: https://edtl.fcsh. unl.pt/encyclopedia/metafora. Acesso em fev. 2019.

CHAUÍ, M. Janela da alma, espelho do mundo. In: NOVAES, A. O Olhar. São Paulo: Companhia das letras, 1988.

COSTA, J. X. S.; CAETANO, R. F. A concepção de alteridade em Lévinas: Caminhos para formação mais humana no mundo contemporâneo. Revista Igarapé, n. 3, 2014. Disponível em: http://www.periodicos.unir.br/index. Acesso em jan. 2019.

DELEUZE, Gilles. Crítica e clínica. Tradução de Peter Pál Pelbar. São Paulo: Ed. 34, 1997.

DELEUZE, Gilles. Mil Platôs. Tradução de Peter Pál Pelbart e Janice Caiafa. São Paulo: Ed. 34, 1997.

LÉVINAS, E. Entre nós: ensaios sobre alteridade. Tradução de Pergentino Stefano Pivatto. 3. ed. Rio de Janeiro: Editora Vozes, 2004.

PÉLBART, P. Da clausura do fora ao fora da clausura. São Paulo: Brasiliense, 1989.

PONTY, M. M. A sensação e a projeção das recordações. In: PONTY, M. M.

Fenomenologia da percepção. Tradução de Carlos Alberto Ribeiro de Moura. 5. Ed. São Paulo: WMF/Martins Fontes, 2018. 